\title{
PERANCANGAN SISTEM PENDUKUNG KEPUTUSAN PENANGANAN TREN PENJUALAN PADA PT. DOREMI MUSIC INDONESIA
}

\author{
Yuni Roza*1 \\ Abduh Maulana Mubarok ${ }^{2}$ \\ Tri Rama Halim Santoso ${ }^{3}$ \\ 1,3 Program Studi Teknik Informatika Fakultas Sains dan Teknologi Universitas Raharja \\ ${ }^{2}$ Program Studi Sistem Informasi Fakultas Sains dan Teknologi Universitas Raharja \\ Email: $\underline{* 1}$ yuni.roza@ raharja.info, ${ }^{2}$ Abduh.maulana@ raharja.info, ${ }^{3}$ triramahalim@ $@$ raharja.info
}

\begin{abstract}
ABSTRAK
PT. Doremi Music Indonesia di Kota Tangerang adalah merupakan perusahaan manufaktur yang bergerak pada jual beli perlengkapan alat musik dan aksesoris yang berkaitan. Dikarenakan pemanfaatan informasi data tren yang ada belum maksimal pada proses pengelolaan dan pemanfaatannya dimana yang bertujuan untuk meningkatkan performa value perusahaan pada departemen Sales \&Marketing khususnya Wholesale, oleh sebab itu dilakukan perancangan sistem pengelolaan output data tren serta menunjang keputusan dalam pemetaan area distribusi produk agar lebih maksimal. Penelitian ini menggunakan metode dengan melakukan wawancara dan observasi serta menggunakan metode analisa sistem Critical Success Factor $(C S F$.). Dengan adanya sistem aplikasi penunjang keputusan dalam pengelolaan data tren diharapkan dapat mempermudah pelaksanaan pemetaan dan penentuan langkah prioritas dalam proses penjualan hasil produk dan meningkatkan value perusahaan.
\end{abstract}

Kata Kunci : Penjualan, Pemasaran, Sistem Pendukung Keputusan, Tren, CSF

\begin{abstract}
PT. Doremi Music Indonesia in Tangerang City is a manufacturing company engaged in buying and selling musical instruments and related accessories. Because the utilization of existing trend data information has not been maximal in the management process and its utilization which aims to improve the company's value performance in the Sales \&amp; Marketing department, especially Wholesale, therefore the design of the trend data output management system and support decisions in mapping the product distribution area to be more maximal. This research uses the method by conducting interviews and observations and using critical success factor (CSF) system analysis method. With the application system supporting decisions in the management of trend data is expected to facilitate the implementation of mapping and determination of priority steps in the process of selling product results and increasing the value of the company.
\end{abstract}

Keywords : Selling, Marketing, Decision Support Syestem, Trend, CSF

\section{PENDAHULUAN}

PT Doremi Music Indonesia merupakan perusahaan Sub Distributor yang berfokus pada penjualan alat musik yang terus berkembang dan mengalami peningkatan terhadap permintaan pasar akan kebutuhan alat musik. Akan tetapi secara kualitatif dalam hal penerapan untuk sistem informasi manajemen perencanaan pemasaran atau penjualan di PT Doremi Music

Vol.7 No.1 - Februari 2021 
Indonesia belum menerapkannya dengan baik sehingga masih adanya ketidaksesuaian terhadap permintaan yang seharusnya terpenuhi dan pola pemasaran yang harusnya bisa dimaksimalkan pada akhirnya output kinerja yang telah dihasilkan terhadap data prosedur perencanaan kurang berdampak signifikan terhadap hasil pendapatan perusahaan

Dengan adanya tren aktifitas pasar dapat mengetahui dan memberikan solusi untuk pengembangan terhadap efektifitas dan efisiensi sistem perencanaan komunikasi perihal pola pemetaan penjualan pada aktivitas pemasaran dan pola tren yang timbul di pasar akan dapat memberikan pengevaluasian desain perencanaan aktivitas yang sesuai untuk basis manajemen komunikasi data pada PT Doremi Music Indoensia bagian Departemen Sales and Marketing khususnya divisi Wholesale.

\section{PERMASALAHAN}

PT Doremi Music Indonesia belom menerapkan sistem informasi manajemen perencanaan pemasaran atau penjualan dengan baik sehingga masih adanya ketidaksesuaian terhadap permintaan yang seharusnya terpenuhi dan pola pemasaran yang harusnya bisa dimaksimalkan pada akhirnya output kinerja yang telah dihasilkan terhadap data prosedur perencanaan kurang berdampak signifikan terhadap hasil pendapatan perusahaan

\section{TINJAUAN PUSTAKA}

\section{Pengertian Sistem}

Rahayu dkk, (2018:3) mendefenisikan: "Sistem merupakan suatu himpunan suatu "benda" nyata atau abstrak yang terdiri dari bagian atau komponen yang saling berkaitan, berhubungan, berketergantungan, saling mendukung yang secara keseluruhan bersatu dalam satu kesatuan untuk mencapai tujuan tertentu secara efisien dan efektif'.)".

\section{Pengertian Data}

Adyanata (2016:1) mendefenisikan "Data merupakan fakta - fakta yang menggambarkan suatu kejadian yang sebenarnya pada waktu tertentu".

\section{Pengertian Sistem Informasi}

Giandari dkk, yang dikutip dari Wahyudiono (2018:157) "Sistem informasi merupakan suatu sistem yang berhubungan dengan pengumpulan, penyimpanan dan pemrosesan data, baik yang dilakukan secara manual, maupun adanya bentuk komputerisasi untuk menghasilkan nformasi yang sangat berguna bagi proses pengambilan keputusan”.

\section{Pengertian Perancangan Sistem}

Yopie dan Ahmadi (2015:3) mendefensikan : "Perancangan sistem adalah tahap lanjutan setelah tahap analisis sistem, proses bertujuan dalam mendefinisikan kebutuhan-kebutuhan yang terpisah kedalam satu kesatuan yang utuh, dan mengkonfigurasikan perangkat yang dibutuhkan dalam perancangan sistem"

\section{Pengertian Pemasaran}

Menurut Thamrin Francis (2016:2) mendefensikan : "Pemasaran adalah suatu sistem total dari kegiatan bisnis yang dirancang untuk merencanakan, menentukan harga, mempromosikan dan mendistribusikan barangbarang yang dapat memuaskan keinginan dan jasa baik kepada para konsumen saat ini maupun konsumen potensial".

\section{Pengertian Segmenting}


Mohamad Dimyati (2018:55) mendefenisikan "Segmentasi pasar adalah proses menempatkan konsumen dalam subkelompok di pasar produk, sehingga pembeli memiliki tanggapan yang hampir sama dengan strategi perusahaan"

\section{Pengertian Targeting}

Mohamad Dimyati (2018:72) mendefenisikan "Targeting adalah menetapkan dan menyepakati target pasar untuk produk yang dihasilkan, yaitu satu atau beberapa segmen pasar yang menjadi fokus

dari kegiatan pemasaran".

\section{Pengertian Pelayanan Komunikasi}

Rian (2015:1) mengatakan:” Integrasi pelayanan komunikasi adalah dasar bentuk pelayanan komunikasi terpusat yang harus ada dalam setiap transaksi komunikasi, dikarenakan bentuk pelayanan komunikasi terpusat menyediakan bentuk pemberian dan penerimaan data ataupun variabel pendukung kegiatan komunikasi yang sesuai dengan aktivitas yang dilakukan sesuai integrasi segala lini aktivitas".

\section{Pengertian Forecasting / Trend}

Murahartawaty dalam kutipan penelitian Ari Nanjaya dkk (2017:2), menjelaskan bahwa forecasting adalah penggunaan data masa lalu dari sebuah variable atau kumpulan variable untuk mengestimasi nilainya di masa yang akan datang, asumsi dasar dalam penerapan teknikteknik pengembangan data".".

\section{Pengertian Sistem Pendukung Keputusan}

Sri Mulyani (2016:11) mendefenisikan: "Sistem pendukung keputusan adalah sebagai dari sebuah sistem yang ditujukan untuk mendukung para pengambil keputusan manajerial dalam situasi keputusan tidak terstruktur".

\section{METODE PENELITIAN}

Pada penelitian ini metode yang digunakan adalah dengan observasi, wawancara dan studi pustaka. Metode analisa sistem yang digunakan adalah Critical Success Factor (CSF). CSF adalah merupakan sebuah metode analisa dengan pertimbangan beberapa hal yang kritis di dalam lingkungan untuk mendefinisikan faktor-faktor apa saja yang mempengaruhi keberhasilan dan kesuksesan perusahaan atau organisasi dan dapat ditentukan jika objektif organisasi telah didefinisakan.

Identifikasi manfaat CSF, antara lain:

1. Mengidentifikasi konsentrasi utama manajemen.

2. Membantu perancangan strategic plan.

3. Mengidentifikasi fokus area dalam tiap rincian project life cycle dan penyebab utama kegagalan proyek.

4. Mengevaluasi kelayakan sistem atau prosedur.

5. Mengidentifikasi ancaman dan kesempatan bisnis.

6. Mengukur tingkat produktifitas sumber daya manusia

Berikut ini adalah daftar literatur review sebagai acuan dalam penelitian :

1. Penelitian oleh Ely Setyo, Putra, Pipik (2017) yang berjudul "Pengembangan Sistem Informasi Peramalan Penjualan Guna Menentukan Bahan Baku Pupuk Menggunakan Metode Triple 
Exponential Smooting”. Penelitian ini bertujuan untuk membantu tingkatan perencanaan atau ramalan produksi pupuk dikalangan petani dalam mendukung permintaan pasar.

2. Penelitian oleh Desta, Riyanto, Primandani, Yusyida, dan Agung (2019) yang berjudul "Sistem Peramalan Penjualan Menggunakan Metode Trend Moment Pada Toko Mebel Nabila Furniture Paguyagan Brebes Berbasis Desktop”, tujuan dari penelitian ini adalah untuk merancang dan membangun sebuah aplikasi untuk peramalan penjualan menggunakan metode trend moment untuk pengambilan keputusan dalam mengetahui jumlah stok mebel di toko, dengan adanya sistem peramalan penjualan barang mebel menggunakan metode trend moment dapat membantu pihak toko dalam pengambilan keputusan tentang pengadaan jumlah stok dan prediksi jumlah penjualan barang pada periode tertentu, sehingga meminimalisir kelebihan atau kekurangan stok pada toko.

3. Penelitian oleh Marsellus O (2019) yang berjudul "Perancangan Aplikasi Forecasting Penjualan Menggunakan Least Equare Method (Studi Kasus Pada Toko Aneka Sari Rantepao)". Penelitian ini bertujuan untuk merancang sebuah aplikasi dalam peramalan penjualan barang pada toko menggunakan metode least equare method yang disajikan dalam tampilan data grafis pergerakan tren yang digunakan untuk memperkirakan estimasi penjualan barang tertentu pada masa yang akan datang berdasarkan penjualan sebelumnya.

4. Penelitian Stavros dan Alan Dix (2018), dalam jurnl internasional International Journal of Forecasting dengan judul "Forecasting Support System Technologies-in-Practice: A Model Of Adoption and Use for Product Forecasting", Penelitian ini berfokus pada penyesuaian faktorfaktor yang berpengaruh penting terhadap pemanfaatan penggunaan Forecasting Support System (FSS) dalam peramalan sebuah produk, pemanfaatan penggunaan aplikasi dalam peramalan produk kedepannya dapat menjadikan data pendukung untuk menghasilkan tingkat penggunaan yang lebih optimal dalam pengambilan keputusan pada sebuah perusahaan.

Dapat disimpulkan dari 4 (empat) Literature Review diatas bahwa permasalahan tentang pengarsipan memiliki fungsi yang penting dalam menunjang proses administrasi dan manajemen suatu instansi.

5. Penelitian Prapai Sridama dan Chopaka Siribut (2018:1) dalam International Journal of anagement Science yang berjudul "Decision Support System For Customer Demand Forecasting and Inventory Management of Perishable Goods". Penelitian ini dilatar belakangi untuk menentukan dan membantu manajemen mempelajari sistem pendukung keputusan untuk mengetahui tren dan inventaris permintaan pelanggan barang yang mudah rusak, penggunaan metode single explonential smooting algorithm memiliki keuntungan lebih dari sistem lama yang diberkan model untuk memetakan model barang tahan lebih lama.

\section{PEMBAHASAN DAN HASIL}

Setelah menganalisa permasalahan yang terjadi saat ini pada PT Doremi Music Indonesia dibutuhkan sebuah model perancangan sistem pendukung keputusan yang sesuai dengan kebutuhan dan mampu memberikan solusi untuk tren pasar mulai dari tahapan pengumpulan informasi, analisa sistem. diagram database dan model perancangan sistem serta pengambilan sebuah keputusan. 


\section{Perancangan Sistem}

\subsection{Use Case Diagram}

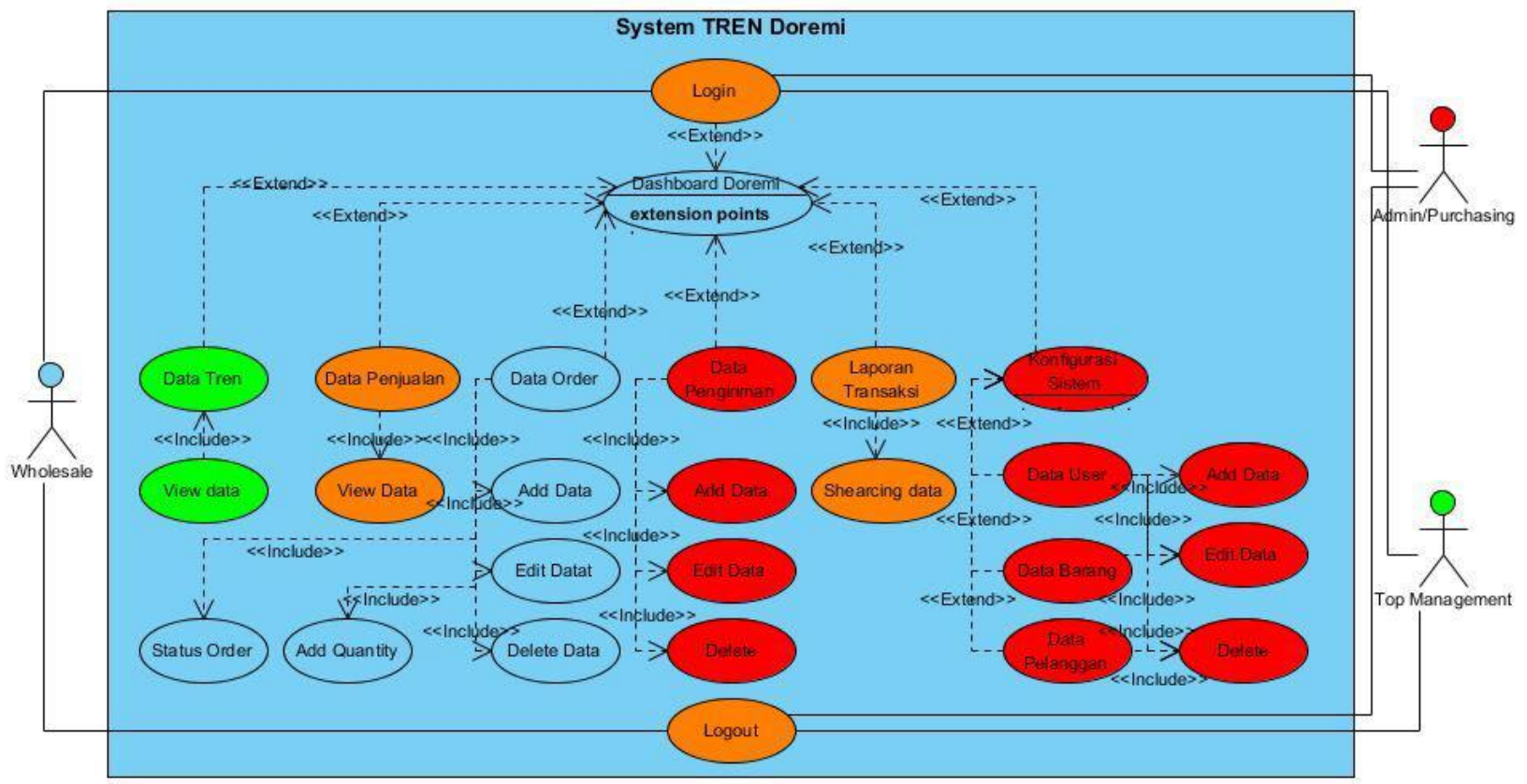

Gambar 1 Use Case Diagram Sistem Yang Diusulkan

Keterangan gambar 1:

1. 1 (Satu) sistem yang meliputi seluruh kegiatan sistem keputusan

2. Use case login pada user/pengguna untuk keamanan sistem agar sistem diakses oleh penggunak yang berhak mengaksesnya

3. Pengelolaan Data Order yang dilakukan oleh pelaksana unit Wholesale saat pelaksanaan pemasaran \& kunjungan kerja pada customer

4. Actor Admin \& Purchasing, merupakan end user yang memiliki hak akses proses inputan transaksi

5. Actor Top Management adalah end user yang memiliki aktifitas pada hak sistem

\subsection{Activity Diagram Pelaksana Wholesale}




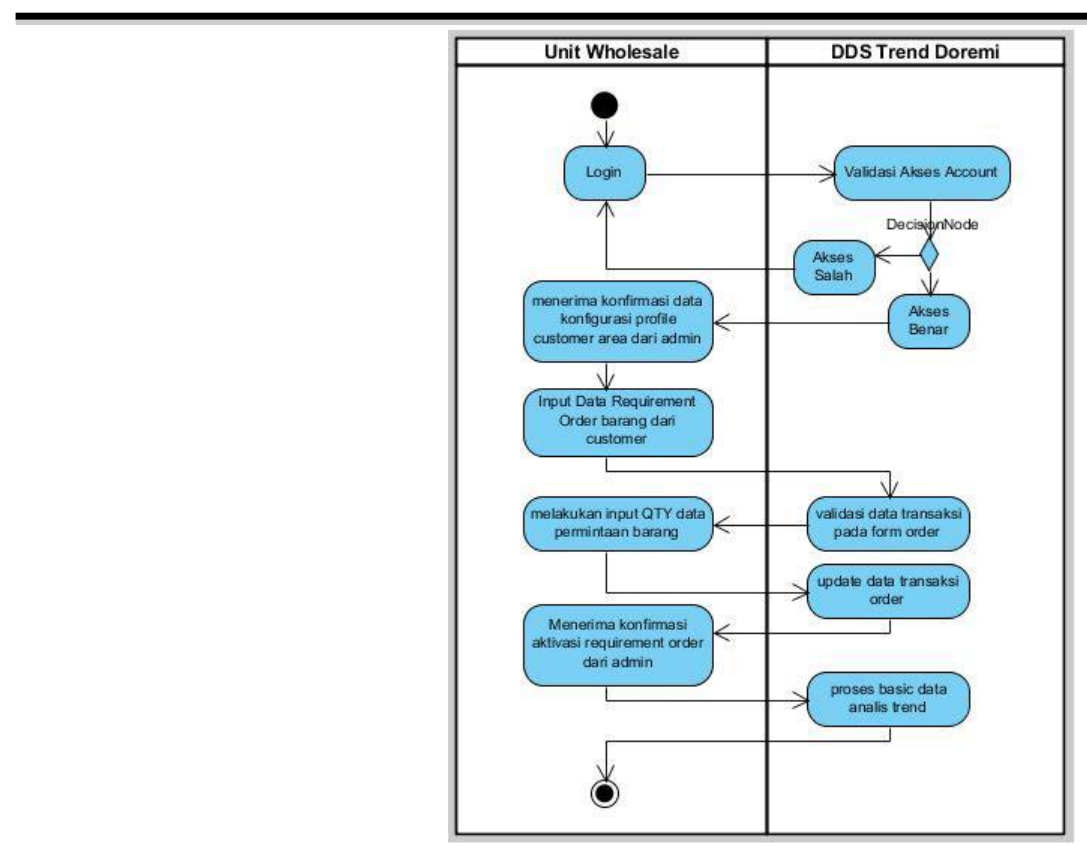

Keterangan gambar 2:

Gambar 2 Activity Diagram Pelaksana Wholesale

Gambar di atas memiliki 11 (sebelas ) action yaitu : Menjelaskan aktivitas yang dilakukan oleh Unit Wholesale yang berfokus pada proses konfirmasi data customer area baru dan pelaksanaan input data requirement order dari customer. Aktivitas ini sebagai langkah awal dalam pengolahan data tren pasar dalam penjualan produk PT Doremi Music Indonesia, sehingga nantinya menghasilkan data tren pergerakan penjualan pada area distribusi produk

\subsection{Activity Diagram Pelaksana Administrasi \& Purchasing}

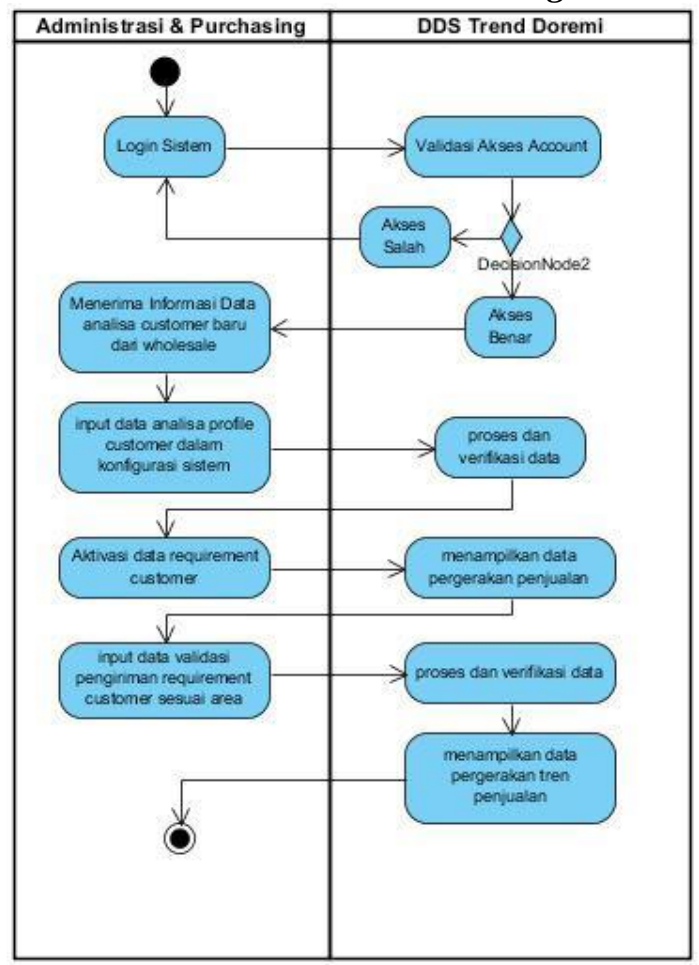

Gambar 3 Activity Diagram Administrasi \& Purchasing 
Keterangan gambar 3:

Terdiri dari 12 (dua belas) action dimana aktivitas yang dilakukan oleh Pelaksana Administrasi \& Purchasing, yang inti aktivitasnya pada proses Aktivasi data requirement customer dan pelaksanaan input data validasi pengiriman produk kepada customer, proses ini untuk melengkapi perolehan data final dalam data analisa progress tren penjualan di lingkungan PT Doremi Music Indonesia.

\subsection{Activity Diagram Top Management}

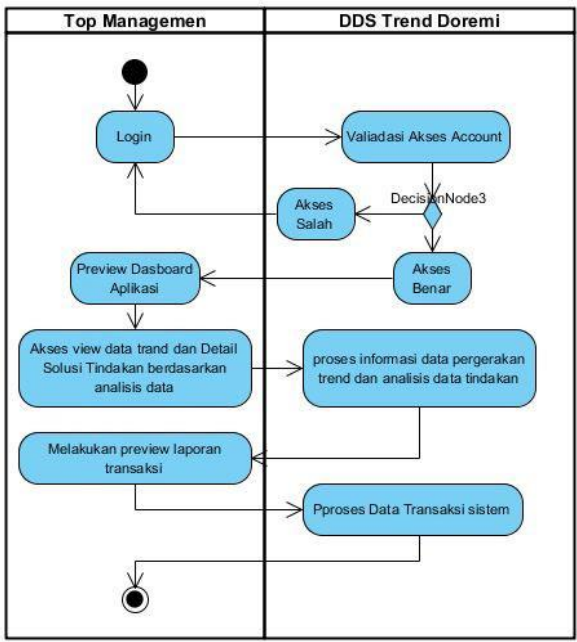

Keterangan gambar 4:

Gambar 4 Activity Diagram Top Management

Terdiri dari 9 (sembilan) action yaitu : Menampilkan aktivitas top management PT Doremi Music Indonesia pada sistem DSS Tren Doremi yang berfokus pada fungsional level monitoring informasi pergerakan data tren penjualan yang ada, proses ini top management dapat mengetahui presentase trend data yang ada dan tindakan solutif apa yang dihasilkan dari analisa data sistem DSS Tren beradasarkan 90 kriteria-kriteria yang telah di tentukan oleh perusahaan dalam menangani kondisi permintaan pasar penjualan produk.

\subsection{Sequence Diagram Sistem Yang Diusulkan}


ISSN: 2461-1409

Online ISSN: 2655-5298

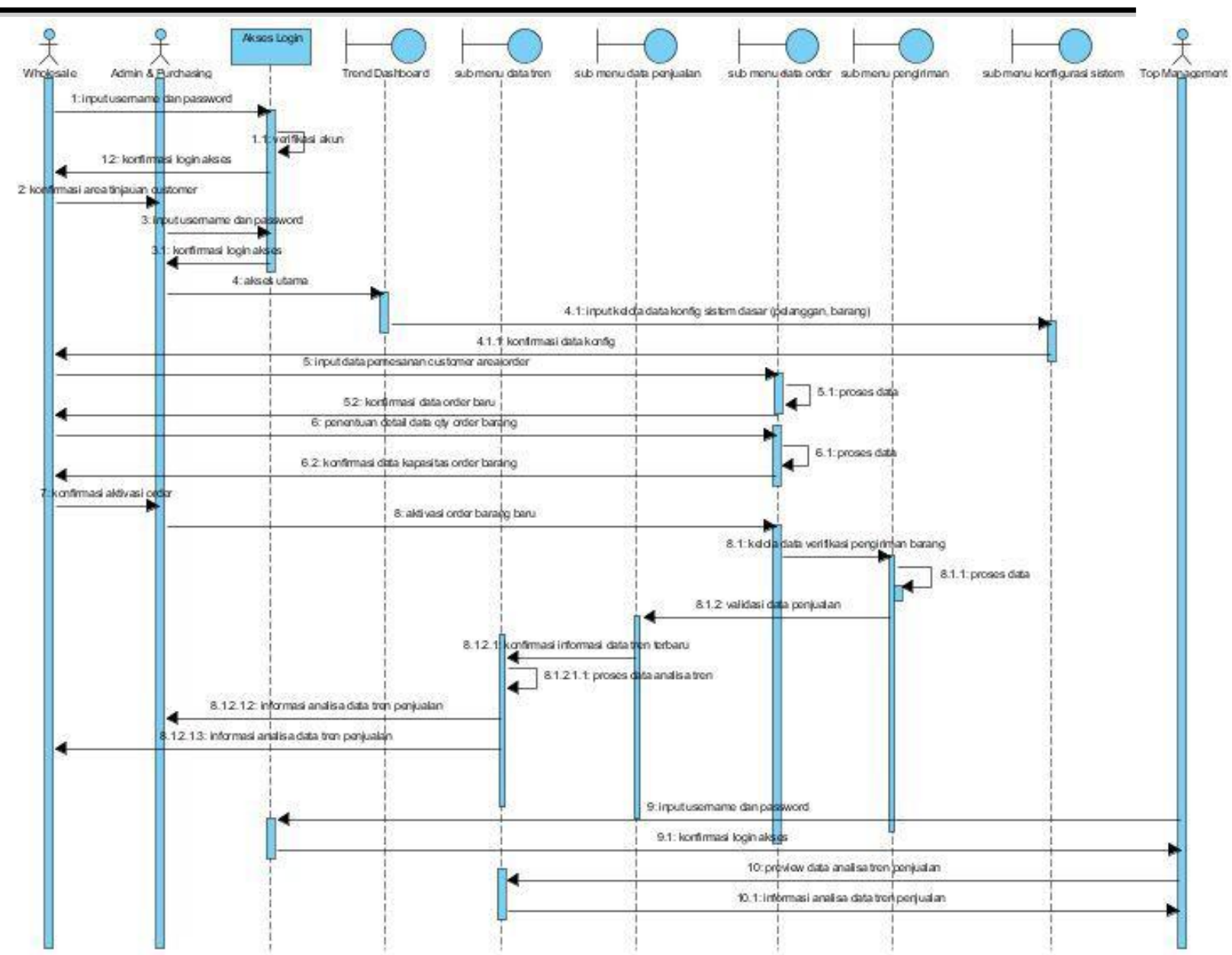

Gambar 5 Sequence Diagram Sistem Yang Diusulkan

Keterangan gambar 5:

Terdiri dari 7 lifeline yaitu : Login, Trend dashboard, submenu data trend, submenu data penjualan, sub menu data order, sub menu pengiriman, sub menu konfigurasi sistem

\subsection{Class Diagram Sistem Yang Diusulkan}

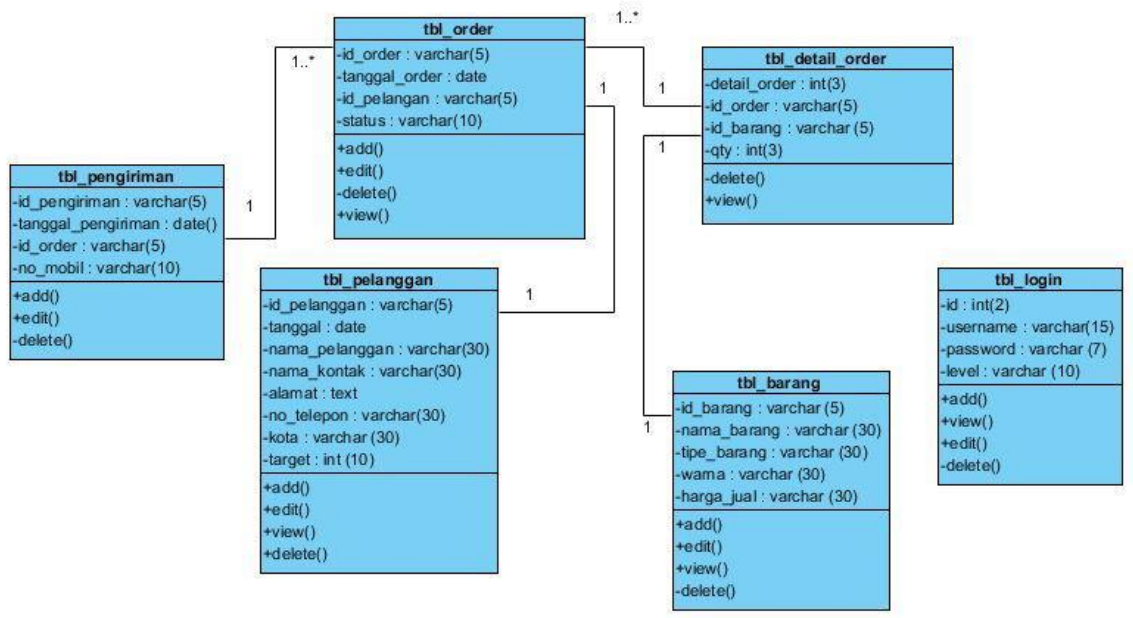

Gambar 6 Class Diagram yang Diusulkan 
ISSN: 2461-1409

Online ISSN: 2655-5298

Keterangan gambar 6:

1. Terdapat 6 (Enam) Class yaitu table pengiriman, order, detail order, login,barang dan pelanggan.

\section{Implementasi}

\section{Tampilan menu Login}

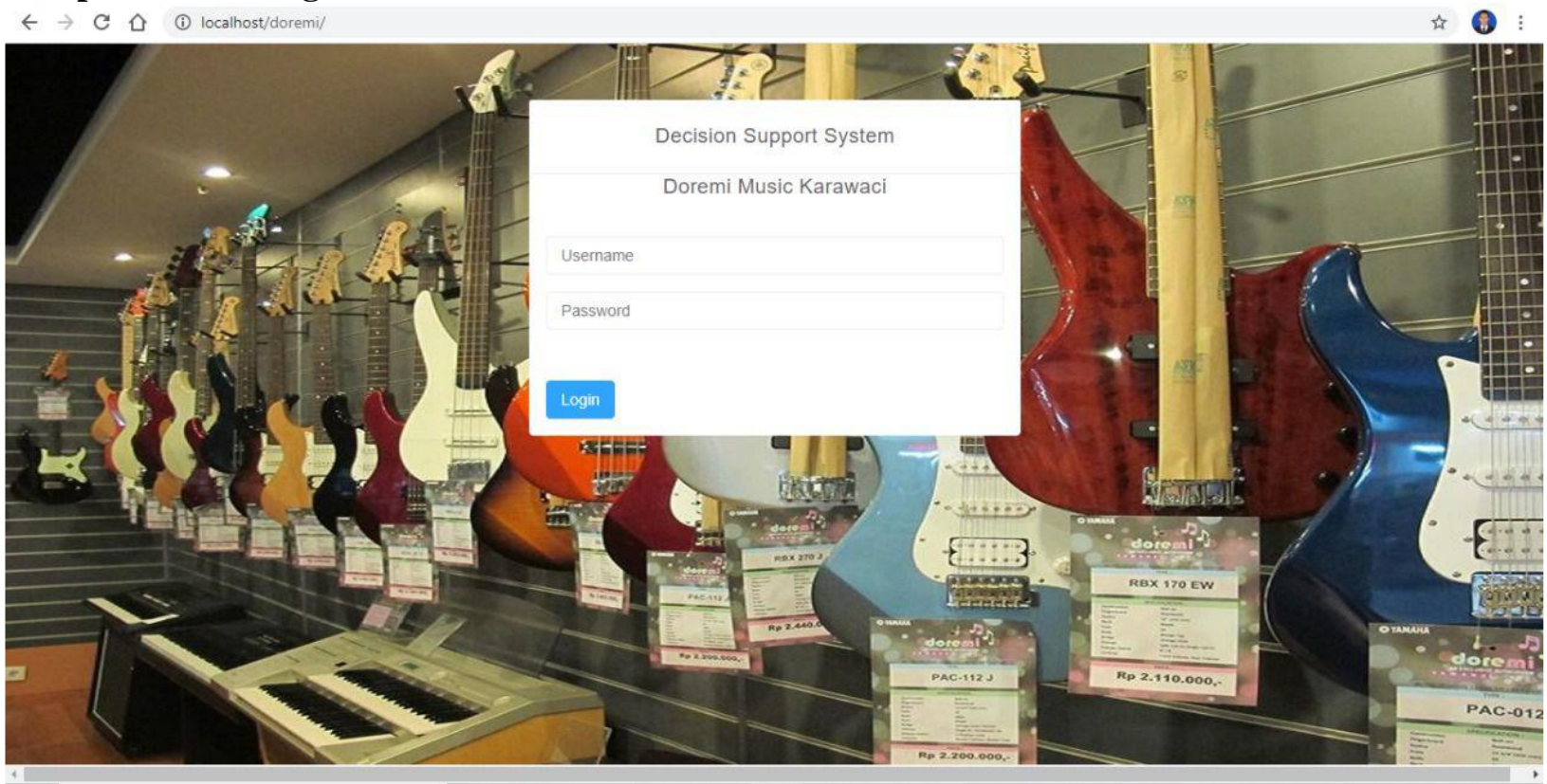

Gambar 7 Tampilan Menu Login

Gambar di atas menjelaskan tentang tampilan pada login dimana user memasukkan username dan password agar bisa masuk ke dalam sistem

\section{Tampilan Dashboard}

DOREMI MUSIK INDONESIA

D॰REMI

Data Tren
Datansaksi
Data Pengiriman
Data Penjualan
Data Laporan Transaksi
Konfigurasi Sistem
Data User
Data Barang
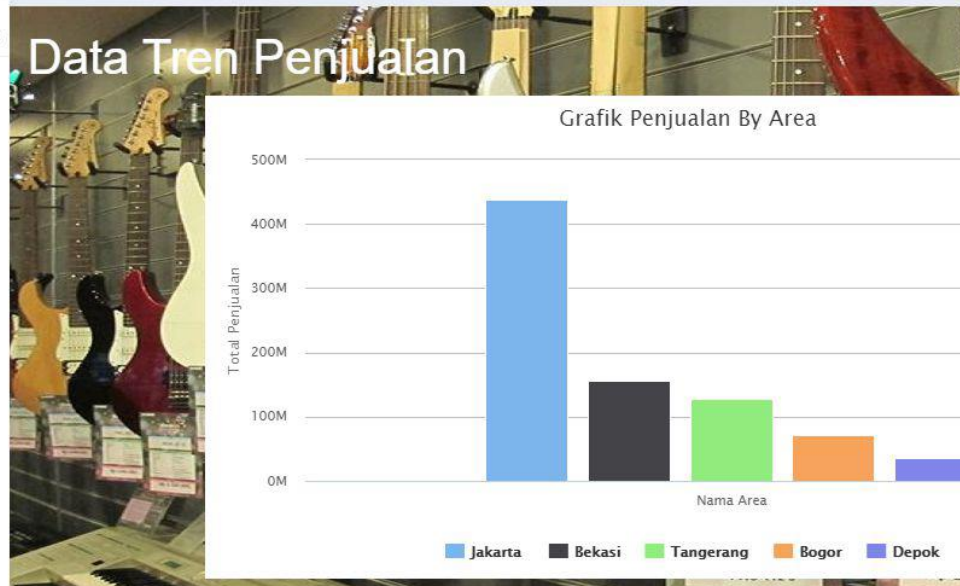

Grafik Penjualan By Area

$\equiv$
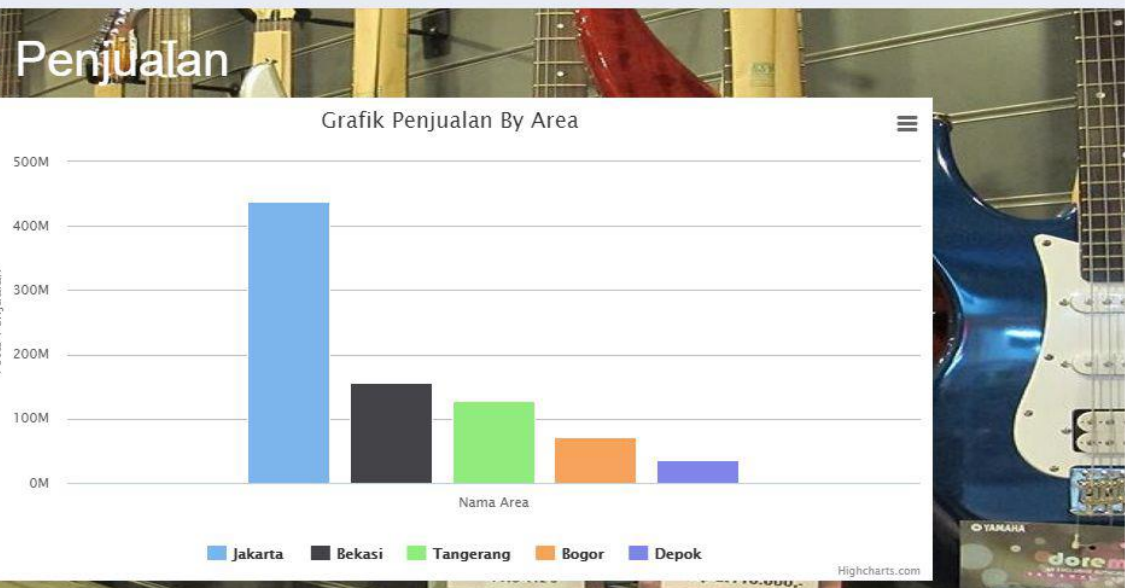
ISSN: 2461-1409

Online ISSN: 2655-5298

Keterangan gambar 8:

Gambar 8 Tampilan Dashboard

Pada halaman ini semua user dapat melihat detail informasi perihal tren penjualan yang ada.

\section{Tampilan Form Input Detail Order}

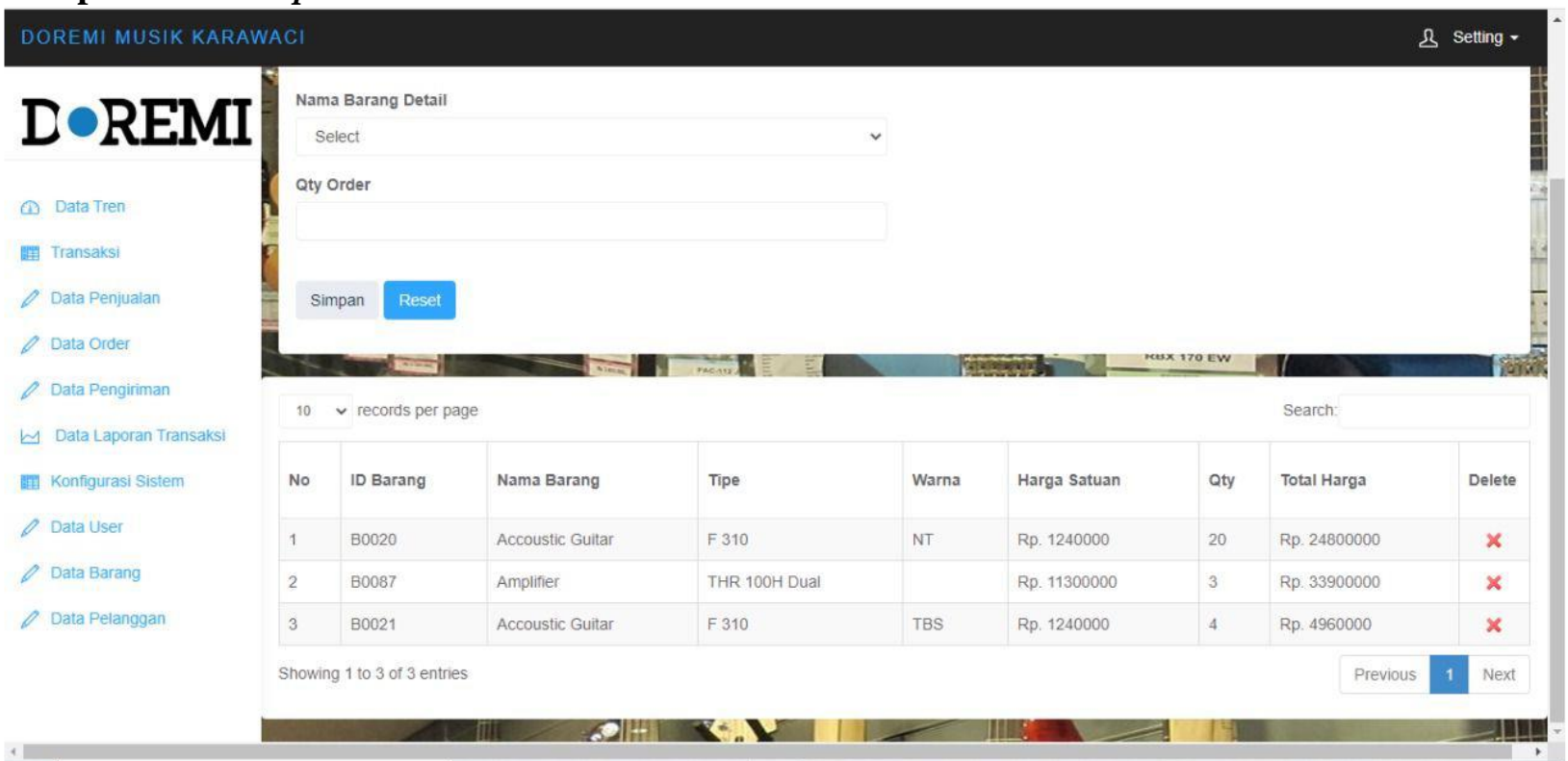

\section{Gambar 9 Form Input Detail Order}

Keterangan gambar 9:

Merupakan form input data detail order barang yang ingin dipesan atau didistribusikan terhadap permintaan customer. Untuk tahap selanjutnya status permintaan yang sebelumnya waiting diwajibkan mengganti dengan status menjadi permintaan diterima melalui form yang telah di sediakan.

\section{Tampilan Menu Tinjauan Data Pengiriman/ Distribusi}

\section{D॰REMI}
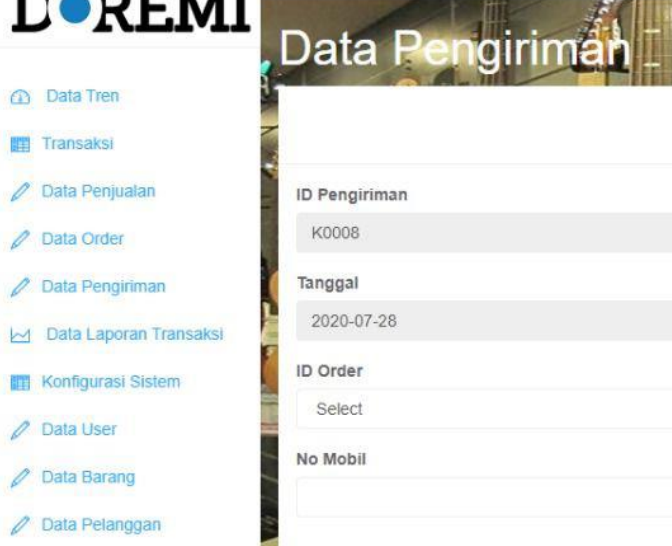

Vol.7 No.1 - Februari 2021 


\section{Gambar 10 Tampilan Menu Tinjauan Data Pengiriman/ Distribusi}

\section{Keterangan Gambar 10:}

Halaman ini menampilkan form pendataan distribusi barang atas permintaan customer sehingga menjadikan siklus data pemasaran penjualan menjadi valid untuk kemudian menjadi database data Analisa sistem tren, yang kemudian data distribusi tersebut akan ter record pada sistem,

\section{Tampilan Report Transaksi}

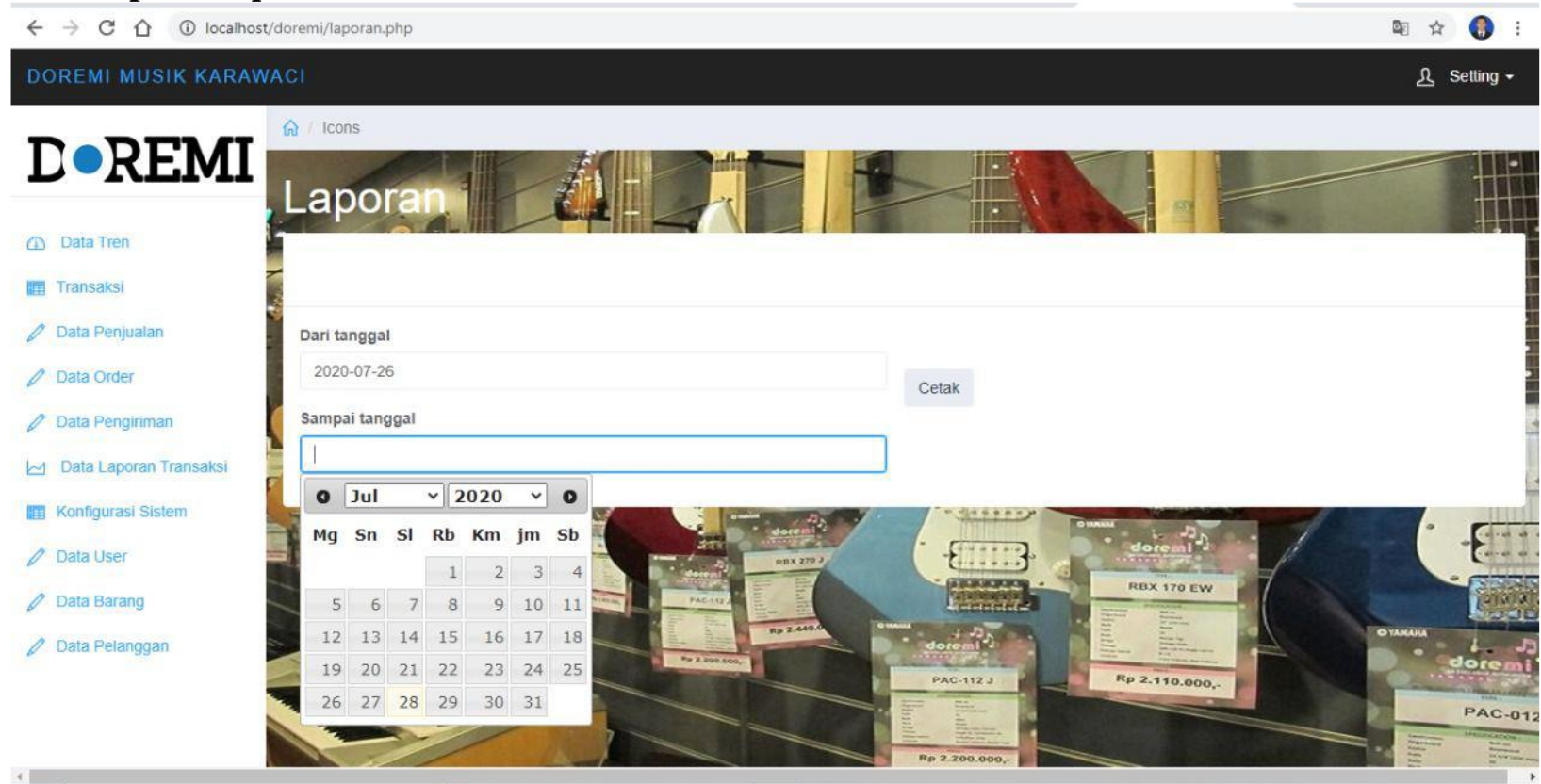

Gambar 11 Tampilan Laporan Transaksi

Keterangan gambar 11:

Pada halaman menu laporan transaksi berfungsi untuk menentukan dasar rancangan generate laporan transaksi yang ada pada aplikasi tren penjualan PT Doremi Music Indonesia, dengan hasil output berupa data dokumen .pdf

\section{KESIMPULAN}

Kesimpulan penelitian ini adalah:

1. Komunikasi transaksi yang sedang berjalan telah menerapkan komunikasi 2 arah yang melibatkan personal pelanggan maupun manajemen perusahaan, namun pola untuk memaksimalkan data observasi lapangan dalam penetapan tingkat performa yang ada masih dalam kondisi kurang efisien, dikarenakan belum adanya pola centralisasi data.

2. Penentuan skema lokasi pemasaran pada Departemen Sales \& Marketing divisi Wholesale PT. Doremi Music Indonesia tidak adanya struktur pendataan basis data perusahaan yang baik dalam pendokumentasiannya, basis data yang saat ini berjalan sering kali terjadi tumpang tindih serta tidak ada integrasi dan updating data secara berkala, terkadang basis data yang ada tidak bisa dijadikan data tinjauan dalam penentuan lokasi pemasaran produk berikutnya, sehingga penentuan lokasi pemasaran produk pada area yg ingin dituju menggunakan data random.

3. Penetapan pola perencanaan kegiatan pemetaan promosi dan maksimalisasi basis data yang dihasilkan pada tahap proses penjualan produk seharusnya dapat dimanfaatkan lebih maksimal 
dengan adanya penggunaan media teknologi, sistem tersebut diformulasikan sebagai sistem penunjang keputusan terhadap area pemetaan yang harus diprioritaskan dan yang tidak diprioritaskan sebagai peluang penjualan produk, , sehingga lebih efisien dalam pelaksanaan kerja dan lebih aman dalam pendokumentasian data.

4. Basis data yang difungsikan dalam penentuan pola perencanaan komunikasi kinerja penjualan dan promosi dapat diperuntukkan dengan penyesuaian variabel-variabel transaksi yang memiliki karakteristik data yang sama untuk kemudian dijadikan dalam bentuk data yang terintegrasi antara proses kinerja satu dengan kebutuhan data proses kerja yang lain, pembentukan sebuah sistem informasi penunjang keputusan yang memiliki fungsional selain sebagai media platform pengolahan administrasi secara integrase juga sebagai media preview penilaian performa capaian kinerja divisi Wholesale PT Doremi Music Indonesia.

\section{DAFTAR PUSTAKA}

[1] Rahayu, Sri, Ai Ratna Sari, dan Tri Sendra Saputra. 2018. "Analisa Sistem Informasi Pengelolaan Keuangan Pada Upt Dinas Pendidikan Kecamatan Neglasari Kota Tangerang". Jurnal SENSI Vol. 4 No. 1 - Februari 2018

[2] Lubis, Adyanata. 2016. "Basis Data Dasar". Yogyakarta:

[3] Yopie, Windha Fransiska, dkk. 2015. "Perancangan Sistem Informasi Peminjaman Buku Pada Perpustakaan Smk Negeri Kebonagung”. Jurnal IJNS Vol. 4 No.1.

[4] Abdullah, Thamrin dan Francis Tantri. 2016. "Manajemen Pemasaran". Depok : PT Raja Grafindo Persada.

[5] Dimyati, M Mahmud. 2018. "Psikologi - Teori". Yogyakarta: Andi

[6] Rian. 2018. "Pelayanan Komunikasi". Online DataBase Article.

[7] Nanjaya, Ari Muhamad. Tasya Aspirati. Koesdining, Nining. 2017. "Analisis Peramalan Volume Produksi Brownies Cheese Cream Dengan menggunakan Metode Adjusted Exponential Smooting Untuk Meminimumkan Kesalahan Peramalan Di Brownies Amanda". Bandung : Jurnal Ilmiah Manajemen, UIB. Vol 3 No.2 1009-1012.

[8] C. Prof. Dr. Sri Mulyani. 2016. “Metode Analisis dan Perancangan Sistem”. Bandung: Abdi Sistematika 